\title{
Universiteit
}

Leiden

The Netherlands

\section{Repertory grid en sentence completion: twee kwalitatieve methoden in de Caraïbische praktijk}

Jaffe, R.K.

\section{Citation}

Jaffe, R. K. (2005). Repertory grid en sentence completion: twee kwalitatieve methoden in de Caraïbische praktijk. Kwalon. Tijdschrift Voor Kwalitatief Onderzoek In Nederland, 29(10), 22-29. Retrieved from https://hdl.handle.net/1887/19029

Version:

Not Applicable (or Unknown)

License:

Leiden University Non-exclusive license

Downloaded from: $\quad$ https://hdl.handle.net/1887/19029

Note: To cite this publication please use the final published version (if applicable). 
De rubriek onderzoek in de praktijk presenteert kwalitatief onderzoek uit Nederland en België, met de bedoeling de lezers te informeren en te inspireren. Wie een bijdrage aan deze rubriek wil leveren, kan contact opnemen met Griet Verschelden. E-mail: griet.verschelden@ugent.be

\section{Repertory grid en sentence completion: twee kwalitatieve methoden in de Caraïbische praktijk}

Rivke Jaffe

In dit artikel bespreek ik het gebruik van twee kwalitatieve cognitieve methoden, namelijk repertory grid en sentence completion, die ik in 2003 en 2004 toepaste tijdens veldwerk in Willemstad, Curaçao en Kingston, Jamaica. Dat veldwerk was onderdeel van een onderzoek naar stedelijke milieuproblematiek op de Caraïben. In dit onderzoek bestudeerde ik actoren op twee gegeneraliseerde niveaus: supralokaal en lokaal. Op supralokaal niveau waren dat overheidsorganisaties en NGO's, op lokaal niveau vier achterstandswijken (twee op elk eiland). De genoemde methoden werden toegepast bij het onderzoek in deze wijken. De selectie van deze locaties was gebaseerd op hun sociaal-economische kenmerken en de nabijheid tot milieuproblemen, en op fysieke en sociale toegankelijkheid. Op Curaçao lag één wijk benedenwinds van een olieraffinaderij, met verstrekkende gevolgen voor de gezondheid van bewoners. De andere wijk, gelegen aan de rand van de stad, heeft een degraderende sociale en fysieke infrastructuur, wat onder andere tot uitdrukking komt in afvalproblematiek en hoge geweld- en misdaadcijfers. De eerste Jamaicaanse wijk grenst aan de grootste vuilstortplaats van het eiland, terwijl de tweede een stedelijke vissergemeenschap is, die grenst aan de vervuilde haven van Kingston en veel last ondervindt van de gebrekkige riolering die daarop uitkomt.

In elke wijk werden circa dertig uitgebreide interviews gehouden, waarbij gebruik werd gemaakt van zowel kwantitatieve als kwalitatieve benaderingen, afhankelijk van de situatie. Het onderzoek op wijkniveau was gericht op lokale percepties, attitudes en overtuigingen van bewoners ten opzichte van hun milieu of environment. Dit laatste begrip werd breed geïnterpreteerd, als de stedelijke omgeving in ruimere, niet strikt ecologische, zin. Interviews handelden over de gemeenschap waarin respondenten woonden, hun stad, natuur en milieuproblemen op hun eiland; en over natuur en milieu in abstracte zin. Percepties en constructies van de stad en haar wijken werden specifiek onderzocht met behulp van de repertory grid method (in twee wijken) en sentence completion exercises (in alle vier de onderzoekswijken).

\section{Repertory grid methode}

Om inzicht te krijgen in de manier waarop de (stedelijke) omgeving wordt gepercipieerd, geconstrueerd en beoordeeld, maakte ik gebruik van repertory grid methodology, een semi-kwalitatieve, gemakkelijk te kwantificeren methode die oorspronkelijk binnen de psychologie werd ontwikkeld, maar ook goed bruikbaar is in de cognitieve antropologie. Deze methode is gebaseerd op de theorie dat mensen hun wereld cognitief ordenen met behulp van dual polarities; zij organiseren verscheidenheid op basis van overeenkomsten en verschillen (Antweiler, 2002: 255). 
Eerst worden constructen ontlokt door de presentatie van triads of drie-eenheden (van woorden, concepten, foto's, enzovoort). Hierbij wordt respondenten verzocht om aan te geven welke twee van de drie voorwerpen 'hetzelfde zijn' of 'bij elkaar passen', en welk object anders is en niet erbij past (Bernard, I995: 245). Als de objecten eenmaal zijn gesorteerd, vraagt men de respondent uit te leggen waar het verschil/de overeenkomst in ligt. Dit antwoord vormt één pool en de respondent wordt gevraagd het tegengestelde van deze pool te onderscheiden, wat leidt tot een constructpaar. De onderzoeker vraagt dan welke pool van het constructpaar 'wenselijk' of 'goed' is, en welke niet; op deze wijze worden normatieve associaties nagegaan (Antweiler, 2000: I21, 2002: 256).

Potter heeft de repertory grid method gebruikt in Barbados, 'to identify the dimensions of appraisal that were being employed in evaluating and comparing areas or environments'. Als 'objecten' gebruikte hij hierbij de elf provincies of parishes van het eiland, waarvan hij de namen presenteerde aan tien respondenten in random geselecteerde drie-eenheden. Door dit gebruik van de repertory grid method, ontlokte hij verscheidene dimensions of appraisal van constructen (Potter, 1992, 2000: 104-I05).

In mijn interviews heb ik deze benadering aangepast door wijken als stimuli te gebruiken. De wijk (op Curaçao de bario, op Jamaica de community genoemd) is op beide eilanden de meeste gangbare, zo niet de primaire maat van sociaalruimtelijke differentiatie, en werd daarom gekozen als eenheid. Ik legde respondenten drie-eenheden van kleine kaartjes voor, met daarop de namen van veertien wijken ${ }^{\mathrm{I}}$. De gekozen wijken moeten uiteraard bij de respondenten bekend zijn en daarnaast ook enige verscheidenheid tonen - de onderzoeker moet dus al enigszins bekend zijn met de stad. Bij het voorleggen werd aan de respondenten gevraagd: 'Welke twee van deze drie wijken lijken het meest op elkaar? Waarom? Geeft $\mathrm{u}$ een voorkeur aan de ene soort wijk boven de andere?' Hierbij werd gevraagd om 'gewoon het eerste te zeggen wat in uw hoofd opkomt' en benadrukt dat er geen goede of foute antwoorden waren. Zo kon een respondent bijvoorbeeld antwoorden dat Wishi en Santa Rosa rustige wijken zijn, en Saliña een drukke, en daarna aangeven dat zij rustige wijken prefereerde. De constructen die op bovenstaande wijze werden ontlokt, onthullen de manier waarop de stad wordt gepercipieerd en geconstrueerd. In de eerste Jamaicaanse wijk legde ik respondenten zeven triads voor, maar dit bleek nogal veel tijd in te nemen, zodat ik me in Willemstad beperkte tot vijf triads.

Deze methode leidt tot een groot aantal constructparen die vervolgens kunnen worden gecategoriseerd en geanalyseerd. Ik deed dit door alle paren op papier uit te printen en te sorteren naar de meest in het oog springende categorieën; in dit geval waren vooral de grootste categorieën van geweld/misdaad, ontwikkeling en activiteitsniveau erg opvallend (zie hieronder). Hierin ligt wel, zoals bij elke categorisering, het gevaar van de bias van de onderzoeker. Ik verdenk bijvoorbeeld Potter (1992) ervan dat hij alle constructparen die zijn ideeën niet ondersteunden, in de categorie 'overig' heeft verstopt. Het is mogelijk om, na afloop van het onderzoek, de categorisering van constructparen ook door respondenten te laten uitvoeren (member check). Ik heb dit echter niet gedaan omdat ik op het tijdstip van analyse weer in Nederland was; wel heb ik met andere onderzoekers overlegd.

In de Curaçaose wijk resulteerde de methode in een lijst van 135 constructparen. De hierbo- 
ven beschreven analyse van deze lijst maakte het mogelijk de paren te sorteren in zeven categorieën, namelijk activiteitsniveau; ontwikkeling; geweld/misdaad; functie; locatie; buitenlanders en overig. Voorbeelden van constructparen en bijbehorende categorieën worden gegeven in Tabel I. Sommige paren bestonden uit meerdere constructen, zodat zij in twee paren werden gesplitst en tweemaal geteld, met als gevolg een totaal van I44. In de Jamaicaanse wijk leidde de methode tot een lijst van 210 constructparen, die na analyse in zeven categorieën vielen die grotendeels overeenkwamen met die op Curaçao. Echter de categorie buitenlanders ontbrak, en er was een kleine maar duidelijke categorie gerelateerd aan bekendheid van respondenten met wijken. Weer bestonden sommige paren uit meerdere constructen, na splitsing leidde dit tot een uiteindelijk totaal van 222 constructparen.

\section{Tabel $1 \quad$ Voorbeelden van constructparen}

\begin{tabular}{|c|c|c|c|c|}
\hline \multirow[b]{2}{*}{ Categorieën } & \multicolumn{2}{|c|}{ Constructparen Jamaica } & \multicolumn{2}{|l|}{ Constructparen Curaçao } \\
\hline & Positieve pool & Negatieve pool & Positieve pool & Negatieve pool \\
\hline Geweld/Misdaad & $\begin{array}{l}\text { geweldloos } \\
\text { vredig } \\
\text { minder oorlog }\end{array}$ & $\begin{array}{l}\text { geweld } \\
\text { ruw } \\
\text { meer oorlog }\end{array}$ & $\begin{array}{l}\text { rustig } \\
\text { mensen wonen er } \\
\text { veilig, rustig }\end{array}$ & $\begin{array}{l}\text { erg slecht } \\
\text { drugs, onderwereld } \\
\text { geweld, prostitutie }\end{array}$ \\
\hline Ontwikkeling & $\begin{array}{l}\text { uptown } \\
\text { chique woonbuurt } \\
\text { goede kleine huisjes }\end{array}$ & $\begin{array}{l}\text { downtown } \\
\text { getto } \\
\text { moet ontwikkelen }\end{array}$ & $\begin{array}{l}\text { arbeiders } \\
\text { ontwikkeld } \\
\text { normaal }\end{array}$ & $\begin{array}{l}\text { chique huizen/geld } \\
\text { afval, lawaai } \\
\text { top }\end{array}$ \\
\hline Activiteitsniveau & $\begin{array}{l}\text { minder druk } \\
\text { koel en rustig } \\
\text { druk, schoon }\end{array}$ & $\begin{array}{l}\text { druk } \\
\text { heet en druk } \\
\text { nuttin' a gwaan (er } \\
\text { gebeurt niks) }\end{array}$ & $\begin{array}{l}\text { rustig } \\
\text { populair } \\
\text { minder moveshon } \\
\text { (beweging, actie) }\end{array}$ & $\begin{array}{l}\text { druk } \\
\text { rustig } \\
\text { moveshon }\end{array}$ \\
\hline Functie & $\begin{array}{l}\text { commercieel } \\
\text { chique woonbuurt } \\
\text { wonen }\end{array}$ & $\begin{array}{l}\text { getto } \\
\text { commercieel } \\
\text { pret, vermaak }\end{array}$ & $\begin{array}{l}\text { wonen } \\
\text { winkels } \\
\text { wonen }\end{array}$ & $\begin{array}{l}\text { winkelen } \\
\text { mensen wonen er } \\
\text { feesten }\end{array}$ \\
\hline Locatie & $\begin{array}{l}\text { centraal } \\
\text { ruraal, heuvel } \\
\text { makkelijk te bereiken }\end{array}$ & $\begin{array}{l}\text { uit de weg } \\
\text { stedelijk } \\
\text { moeilijk te bereiken }\end{array}$ & $\begin{array}{l}\text { centraal } \\
\text { dichtbij } \\
\text { makkelijk te bereiken }\end{array}$ & $\begin{array}{l}\text { ver weg } \\
\text { ver weg } \\
\text { moeilijk te bereiken }\end{array}$ \\
\hline Bekendheid & $\begin{array}{l}\text { bekend } \\
\text { kom ik vaker } \\
\text { leuk, voel me thuis }\end{array}$ & $\begin{array}{l}\text { onbekend } \\
\text { kom ik minder vaak } \\
\text { ontwikkelingsplek }\end{array}$ & nvt & nvt \\
\hline Buitenlanders & nvt & nvt & $\begin{array}{l}\text { echte Curaçaoënaars } \\
\text { familie, rustig leven } \\
\text { minder buitenlanders }\end{array}$ & $\begin{array}{l}\text { buitenlanders } \\
\text { buitenlanders } \\
\text { buitenlanders }\end{array}$ \\
\hline Overig & $\begin{array}{l}\text { interessant } \\
\text { bron van Rasta } \\
\text { meer cultuur, vibes }\end{array}$ & $\begin{array}{l}\text { niet zo interessant } \\
\text { Rasta's meer recent } \\
\text { minder bekende }\end{array}$ & $\begin{array}{l}\text { klein } \\
\text { hou ervan } \\
\text { echte bario (wijk) } \\
\text { mensen }\end{array}$ & $\begin{array}{l}\text { groot } \\
\text { hou er niet van } \\
\text { een plek }\end{array}$ \\
\hline
\end{tabular}


Ik heb ervoor gekozen de verzamelde data kwantificerend te benaderen tijdens de analyse. Ten eerste heb ik gekeken naar het percentage respondenten dat constructparen gebruikt die binnen een bepaalde categorie vallen. Zo bleek op Jamaica dat meer dan tachtig procent van respondenten minstens één keer een construct gebruikte dat in de geweld/misdaadcategorie viel, terwijl op Curaçao iets meer dan de helft van alle respondenten dit deed (zie tabel 2). Ten tweede keek ik naar het percentage van het totaal aantal gebruikte constructparen dat in elke categorie valt. Hierbij wordt dus gelet op het totaal van alle ontlokte constructparen, onafhankelijk van respondenten. Van alle 222 constructparen die op Jamaica werden ontlokt, verwezen er 57, ofwel iets meer dan een kwart, naar geweld of misdaad; op Curaçao ging het om I7 procent van alle paren (tabel 3).

Deze methoden leidden tot ongeveer dezelfde volgorde van categorieën, zoals blijkt uit tabel 2 en 3 . Uit beide benaderingen bleek dat bij het evalueren van wijken, in overweldigende mate termen worden gebruikt die verwijzen naar geweld of criminaliteit, ontwikkeling, functie en activiteitsniveau.

Deze kwantitatieve benadering van constructparen maakt het mogelijk de data grafisch uit te beelden, bijvoorbeeld in staaf- of taartdiagrammen. Een dergelijke weergave, evenals het categoriseren zelf, houdt wel een zeker verlies aan informatie in. Dit kan enigszins ondervangen worden door voorbeelden zoals in tabel I bij te voegen. Er bestaan uiteraard andere manieren om met de data om te gaan dan die waarvoor ik heb gekozen; het is bijvoorbeeld mogelijk schalen te maken, door een ranking te maken van wijken en/of constructen op basis van de positieve en negatieve polen.

Tabel 2 Percentage respondenten dat construct categorie gebruikt ( $n=$ totaal aantal respondenten)

\begin{tabular}{|l|l|l|}
\hline \multirow{2}{*}{ Construct Categorie } & \multicolumn{2}{|l|}{ percentage dat construct gebruikt } \\
\cline { 2 - 3 } & Jamaica $\mathbf{( n = 3 0 )}$ & Curaçao $\mathbf{( n = 2 8 )}$ \\
\hline Geweld/Misdaad & 83.3 & 51.9 \\
\hline Ontwikkeling & 83.3 & 66.7 \\
\hline Functie & 56.7 & 51.9 \\
\hline Activiteitsniveau & 50.0 & 70.4 \\
\hline Locatie & 43.3 & 29.6 \\
\hline Bekendheid & 30.0 & nvt \\
\hline Buitenlanders & nvt & 18.5 \\
\hline Overig & 23.3 & 29.6 \\
\hline
\end{tabular}




\begin{tabular}{|l|l|l|}
\hline Categorie & Jamaica & Curaçao \\
\hline Geweld/Misdaad & $26 \%$ & $17 \%$ \\
\hline Ontwikkeling & $23 \%$ & $19 \%$ \\
\hline Functie & $18 \%$ & $15 \%$ \\
\hline Activiteitsniveau & $11 \%$ & $26 \%$ \\
\hline Locatie & $11 \%$ & $11 \%$ \\
\hline Bekendheid & $8 \%$ & $0 \%$ \\
\hline Buitenlanders & $0 \%$ & $5 \%$ \\
\hline Overig & $4 \%$ & $6 \%$ \\
\hline Totaal & $100 \%$ & $100 \%$ \\
\hline (N) & $(222)$ & $(144)$ \\
\hline
\end{tabular}

\section{Sentence completion methode}

Een volgend onderdeel van elk interview waren de sentence completion exercises; dit onderdeel bestond uit tien zinnen over verschillende wijken, die respondenten moesten afmaken. Voorbeelden zijn 'Marchena is...' 'Als ik in Half Way Tree ben...' of 'In Santa Rosa...' De resultaten van deze methode zijn minder kwantificeerbaar dan de data verkregen via de repertory grid methode, omdat reacties minder duidelijk in afzonderlijke categorieën vallen. Veel zinnen werden voltooid met verwijzingen naar herkenningspunten: de Carib bioscoop, de universiteit, het ziekenhuis in Kingston; het politiebureau, de gevangenis, de Kentucky Fried Chicken in Willemstad. Persoonlijke voor- en afkeuren waren bij deze techniek nog duidelijker dan bij het gebruik van triads: wijken werden geclassificeerd als 'een leuke plek', 'slecht, slecht, slecht' of 'de place to be, ik ben er dol op!' Daarnaast was een aanzienlijk aantal antwoorden opzettelijk neutraal, omdat men niks (slechts) wilde zeggen over wijken die men niet goed kende: 'Het is gewoon, je weet wel, normaal' of 'Ik kan er niet echt iets over zeggen'. Daarentegen geeft sentence completion wel meer ruimte voor uitgebreide antwoorden dan bij de constructie van polen. Over het algemeen kwam de manier waarop zinnen werden voltooid, grofweg overeen met de categorieën die tevoorschijn kwamen bij het vergelijken van wijken in de repertory grid methode. De data verzameld via de sentence completions zijn meer kwalitatief, maar verlenen sterke steun aan de conclusies die men kan trekken uit het repertory grid materiaal. Bovendien bieden zij de mogelijkheid een lijst van evaluaties per wijk op te tekenen. Voor mij waren waarderingen van de eigen wijk het belangrijkst. Daarnaast maken zij het mogelijk een kaart te tekenen van de constructie van de stedelijke omgeving, zoals deze bestaat bij bewoners van de vier onderzochte wijken. Op deze manier wordt het mogelijk een goede ruimtelijke indruk te geven van de percepties van een stad. Figuur I is een voorbeeld van een dergelijke schematische voorstelling van Kingston en geeft een idee hoe wijkbewoners deze buurten evalueren. Een aantal genummerde sleuteltermen vatten de sentence completions samen. 


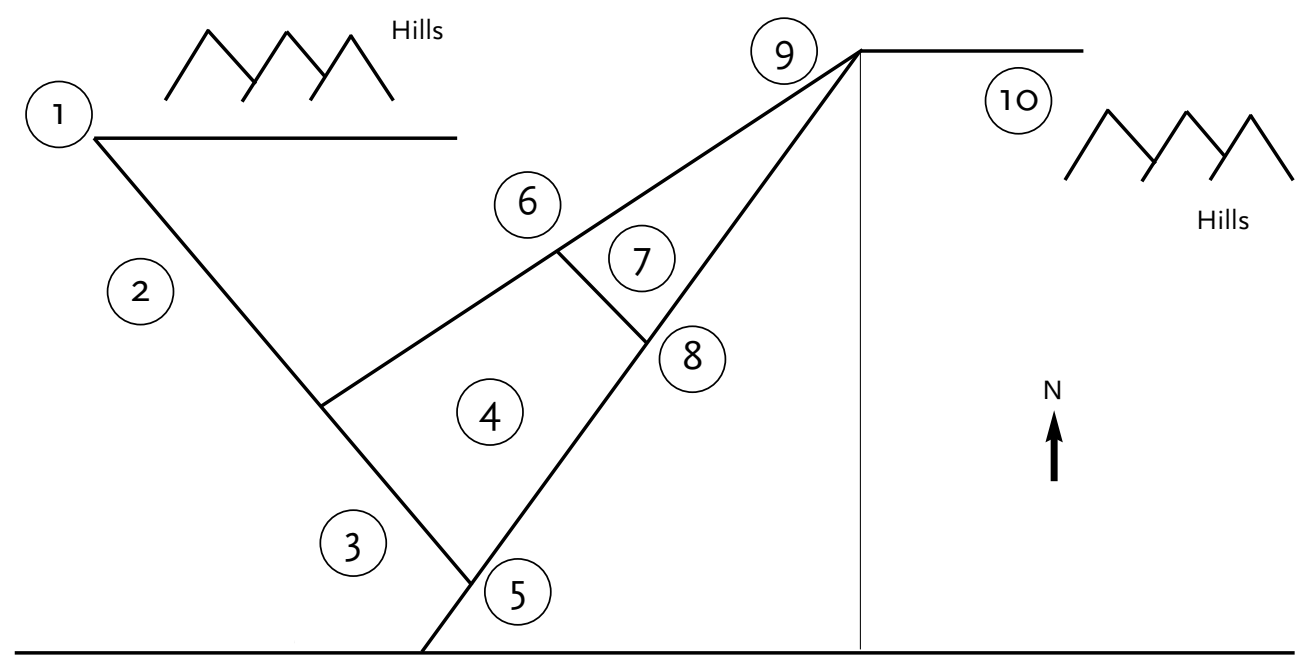

Kingston Harbour

1. Six Miles

2. Riverton

3. Trench Town

4. Tivoli Gardens

5. Downtown

6. Half Way Tree

7. New Kingston

8. Crossroad

9. Liguanea

10. Mona doorreisplek, rivier, vissen, geweld, bush [wildernis] thuis, goed, in ontwikkeling, getto

Bob Marley, cultuur, geweld, familie geweld, oorlog, JLP [politieke partij], goede feesten winkelen, geweld, oorlog zaken, uitgaan, plezier, grens van uptown/downtown uptown, goed ontwikkeld, zaken, prostituees, uitgaan zaken, uitgaan, Carib bioscoop leuk, uptown, chique woonbuurt, winkelen ziekenhuis, universiteit, chique woonbuurt, koel, stil

\section{Reflectie}

In het kader van mijn veldwerk boden de hier beschreven methoden de mogelijkheid inzicht te krijgen in, ten eerste, hoe respondenten hun stedelijk omgeving waarderen en in welke termen zij over de verschillende wijken - afzonderlijk en in vergelijking met elkaar - denken. Hierbij is opmerkelijk dat milieuconstructen (bijvoorbeeld schoon/vies) zo goed als afwezig waren. Maar belangrijker is dat geweld en criminaliteit als voornaamste preoccupaties naar voren komen, samen met 'ontwikkeling', de verschillen in inkomen, infrastructuur en diensten. Verschillen in activiteitsniveau worden hier vaak aan gerelateerd, bijvoorbeeld doordat rustige, dure wijken ook de veilige zijn. Een voorzichtige conclusie die uit de data kan worden getrokken, is dat zelfs in wijken in milieuprobleemgebieden, milieuzorgen lager gewaardeerd worden dan sociaal-economische kwesties. De primaire preoccupaties zijn niet alleen inkomen en ontwikkeling, iets wat men 
in elk arm land of gemeenschap zou kunnen verwachten. Wat opvalt is hoe sterk geweld en misdaad figureren in de repertory grid van respondenten. Een tweede resultaat komt vooral naar voren uit de sentence construction methode met betrekking tot de eigen wijk. Het was interessant te zien dat bewoners, ondanks het feit dat zij allen in gemeenschappen met zeer slecht reputaties woonden in milieuprobleemgebieden, hun eigen wijk vrijwel zonder uitzondering heel hoog waardeerden.

De beschreven methoden hebben een aantal voordelen. Ten eerste zijn zij gemakkelijk te begrijpen voor laagopgeleide respondenten. Ten tweede is het vooral bij de triads vrijwel onmogelijk om 'sociaal wenselijke' antwoorden te geven - de constructen worden niet door de interviewer gesuggereerd of opgelegd, de antwoorden zijn soms ook compleet onverwacht. Hierbij is het wel belangrijk dat de drie-eenheden random worden aangeboden. Percepties van de stedelijke omgeving zijn bij deze methoden veel gemakkelijker te ordenen dan bij open vragen of ongestructureerde interviews, hoewel de onderzoeker, zoals eerder opgemerkt, bij het indelen in categorieën alert moet zijn voor de eigen bias. Daarnaast biedt de combinatie van de twee methoden verschillende mogelijkheden om de data op complementaire wijze te presenteren en te bewerken, bijvoorbeeld door de gegevens te kwantificeren of via een schematische kaart de geografische uitdrukking weer te geven.

De door mij gebruikte variant van de repertory grid methode heeft als nadeel dat de kaartjes met namen van wijken niet geschikt zijn voor analfabeten. Op zowel Curaçao als Jamaica is het niveau van analfabetisme relatief erg laag; slechts één respondent bleek de kaartjes niet te kunnen lezen. In andere samenlevingen kan dit echter wel een bezwaar zijn. Een ander aspect van de repertory grid methode is dat deze ervan uitgaat dat mensen denken in dual polarities, een aanname die niet door iedereen onderschreven wordt. Kritiek op deze veronderstelling is echter vooral gericht op het structuralistische idee van alomvattende, universele dualismes; de repertory grid methode gaat uit van de veronderstelling dat mensen, per cultuur verschillend, een veelheid van contradictoire dualismes kunnen handhaven.

Een nadeel bij de sentence completions is dat respondenten na de eerste zin soms geneigd zijn antwoorden in dezelfde trant te blijven geven als zij merken dat hun eerste respons 'goed' is. Bijvoorbeeld als de eerste zin 'Scharloo is...' wordt voltooid met 'een gevaarlijke wijk', kan de neiging groot zijn om alle volgende wijken naar mate van veiligheid te beoordelen. Dit kan enigszins worden ondervangen door voor de eerste zin een neutrale wijk te kiezen, en door een alerte interviewer die de respondent verzekert dat elk type respons goed is en dat juist wordt gezocht naar spontane associaties.

Hoewel er dus een aantal kanttekeningen geplaatst moeten worden, is door de praktijk van onderzoek in twee Caraïbische steden gebleken dat de repertory grid method en sentence completion exercises waardevolle inzichten kunnen bieden bij het zoeken naar patronen van stedelijke cognitie.

\section{Literatuur}

Antweiler, C. (2000) Urbane Rationalität: Eine Stadtethnologische Studie zu Ujung Pandang (Makassar), Indonesien. Berlin: Dietrich Reimer Verlag.

Antweiler, C. (2002) Rationalities in Makassar, in P.J.M. Nas (ed) The Indonesian Town Revisited. Münster: LIT, 230-285. 
Bernard, H.R. (1995) Research Methods in Anthropology: Qualitative and Quantitative Approaches. Walnut Creek: Altamira.

Potter, R.B. (I992) Caribbean Views on Environment and Development: A Cognitive Perspective. Caribbean Geography 3 236-243.

Potter, R.B. (2000) The Urban Caribbean in an Era of Global Change. Aldershot: Ashgate.

\section{Noten}

I De veertien wijken of communities van Kingston die als stimuli werden gebruikt, waren Riverton, Six Miles, Trench Town, Jones Town, Tivoli Gardens, August Town, Downtown, Liguanea, Jack's Hill, Mona, Papine, Crossroads, Half Way Tree en New Kingston. Op Curaçao warden de volgende veertien wijken of barios gebruikt: Wishi, Marchena, Scharloo, Otrobanda, Berg Altena, St. Jago, Koraal Specht, Rio Canario, Suffisant, Punda, Santa Rosa, Santa Maria, Saliña, en Mahaai.

2 Stimulus-wijken op Jamaica waren het eerste jaar Riverton, Six Miles, Tivoli Gardens, Trench Town, Downtown, Liguanea, Half Way Tree, Crossroads, New Kingston en Mona. Deze wijken werden gekozen omdat ik ervan uitging dat iedereen ze zou kennen. Over het algemeen bleek dit te kloppen, hoewel sommige respondenten niet zeker wisten waar Mona lag. Toen ik deze methode het tweede jaar gebruikte, verving ik Mona en Six Miles (een wijk dicht bij de eerste onderzoekswijk) door August Town and Rae Town. Op Curaçao gebruikte ik het eerste jaar als stimuli Marchena, Wishi, Santa Rosa, Emmastad, Saliña, Koraal Specht, Rio Canario, Seru Fortuna, Otrobanda, Mahaai, Punda, and Suffisant. Wederom werden deze wijken gekozen omdat werd aangenomen dat iedereen ze zou kennen, maar veel respondenten waren van mening dat Suffisant zo dicht bij Rio Canario lag dat het bijna dezelfde wijk was, en wat Santa Rosa betrof meldden veel bewoners slechts dat het ver weg was en dat ze er weinig van wisten. Om deze redenen en ook omdat ik het idee had dat de gebruikte wijken ietwat te uniform waren, gebruikte ik het tweede jaar de wijken Emmastad, Scharloo en Seru Fortuna en schrapte ik Santa Rosa en Suffisant. Ook werden de wijken Wishi en Marchena als één wijk gepresenteerd. Deze veranderingen maken de methode uiteraard minder kwantificeerbaar. 